\title{
A Novel Missense Mutation in the Gene Encoding Major Intrinsic Protein (MIP) in a Giant Panda with Cataracts
}

chao bai

Beijing Key Laboratory of Captive Wildlife Technoloies, Beijing Zoo https://orcid.org/0000-0002-97324276

Yuyan You ( $\nabla$ youyy351@163.com )

https://orcid.org/0000-0002-9607-4236

Xuefeng Liu

beijing zoo

Maohua Xia

beijing zoo

Wei Wang

beijing zoo

Ting Jia

beijing zoo

Tianchun Pu

beijing zoo

Yan Lu

beijing zoo

Chenglin Zhang

beijing zoo

Xiaoguang $\mathrm{Li}$

beijing zoo

Yanqiang Yin

chongqing zoo

Wang Liqin

chongqing zoo

Jun Zhou

chongqing zoo

Lili Niu

chongqing zoo 
Keywords: cataracts, giant panda, major intrinsic protein (MIP)

Posted Date: September 14th, 2020

DOI: https://doi.org/10.21203/rs.3.rs-30524/v2

License: (c) (1) This work is licensed under a Creative Commons Attribution 4.0 International License. Read Full License 


\section{Abstract}

Background: Cataracts are defects of the lens that cause progressive visual impairment and ultimately blindness in many vertebrate species. Most cataracts are age-related, but up to one third have an underlying genetic cause. Cataracts are common in captive zoo animals, but it is often unclear whether these are congenital or sporadic acquired (age-related) lesions.

Results: Here we used a functional candidate gene- screening approach to identify mutations associated with cataracts in a captive giant panda (Ailuropoda melanoleuca). We screened 11 genes often associated with human cataracts and identified a novel missense mutation (c.686G>A) in the MIP gene encoding major intrinsic protein. , whichThis is expressed in the lens and normally accumulates in the plasma membrane of lens fiber cells, where it plays an important role in fluid transport and cell adhesion. The mutation causes the replacement of serine with asparagine (p.229S $>$ Np.S229N) in the C-terminal tail of the protein, and modeling revealed predicts that the mutation- induced induces conformational changes that may interfere with lens permeability and cell-cell interactions.

Conclusion: The c. $686 \mathrm{G}>\mathrm{A}$ mutation was found in a captive giant panda with a unilateral cataract but not in 18 controls from diverse regions of in China, suggesting that c.686G >Ait is likely to bemost likely a genuine disease-causing associated mutation rather than a single-nucleotide polymorphism 5 regions was used in this research.

Conclusions: The $\mathrm{c} .686 \mathrm{G}>\mathrm{A}$ mutation was not found in healthy pandas, suggesting itThe mutation could therefore serve as a new genetic marker to predict the risk of congenital cataracts in captive giant pandas.

\section{Background}

Cataracts are heterogeneous and multifactorial eye lesions in which the lens becomes opaque due to the accumulation of pigments and protein aggregates induced by progressive oxidative damage (Spector 1995, Hejtmancik 1998). Many cataracts are acquired, age-related lesions but approximately one third of cases have a significant genetic component, and most of these congenital forms are transmitted as autosomal dominant traits with strong penetrance but varying degrees of expressivity (Francis et al. 2000a). Although the pathogenesis of cataracts often has a genetic component, the etiology is complex because progression is also influenced by nutrition, metabolism and the environment. Cataract formation is therefore the long-term consequence of multiple intrinsic and external factors. For example, epidemiological studies have shown that human cataract development is promoted by ultraviolet radiation, diabetes, hypertension, cardiovascular disease, body trauma, and excess drinking and smoking.

Whereas some congenital cataracts are caused by the disruption of eye development, others reflect the presence of mutations in genes required for normal lens function (Hejtmancik 1998). For example, in humans, underlying mutations have been detected in genes encoding transcription factors that regulate lens activity, such as PITX3 (Semina et al. 1998) and HSF4 (Bu et al. 2002), and in genes encoding lens 
cytoskeletal proteins, such as BFSP2 (Conley et al. 2000, Jakobs et al. 2000). Several mutations have been traced to genes encoding crystallin proteins, which normally remain soluble and confer transparency, including a-crystallins (Vanita et al. 2006), ß-crystallins (Litt et al. 1997, Lu et al. 2007, Meyer et al. 2009), and $y$-crystallins (Zhang et al. 2007, Yao et al. 2008). Another major category of cataract-promoting mutations affect genes encoding lens membrane channels or gap junction proteins, such as connexin 46 (GJA3) (Burdon et al. 2004) and connexin 50 (GJA8) (Arora et al. 2008). One of the most important membrane channels in the context of cataract formation is the lens major intrinsic protein (MIP), also known as aquaporin 0 (AQP0) (Chepelinsky 2009).

MIP/AQP0 is an integral membrane protein ( $28 \mathrm{kDa}, 263$ amino acids) with six transmembrane domains, which assembles into a tetramer containing four independent water channels (Chepelinsky 2003, Shiels et al. 2001). It is expressed at high levels in lens fiber cells and constitutes $\sim 45 \%$ of the total membrane protein (Bassnett et al. 2009). Its main function is the transport of water and small, neutral solutes (Borgina et al. 1999, Francis et al. 2000b, Mathias et al. 2007), but it is also required for the adhesion of lens fiber cells via interactions with crystallins and connexin 50 (Liu et al. 2008, Kumari \& Varadaraj 2009, Liu et al. 2011). At least 19 mutations in the human MIP gene (Table 1) have been linked to autosomal dominant cataracts with diverse phenotypes, reflecting the multi-domain and multi-functional nature of the protein (Berry et al. 2000, Geyer et al. 2006, Gu et al., 2007, Lin et al. 2007, Jiang et al. 2009, Wang et al. 2010, Wang et al 2011, Xiao et al. 2011, Yang et al., 2011, Senthil Kumar et al. 2013, Zeng et al. 2013, Ding et al. 2014, Yu et al. 2014, Shentu et al. 2015, Song et al. 2015, Qin et al. 2016, Jiang et al. 2017, Long et al. 2017). In many cases, these mutations reduce the abundance of MIP and/or prevent normal trafficking to the plasma membrane, thus inhibiting water and solute transport as well as cell-cell interactions (Francis et al. 2000b, Varadaraj et al. 2008, Senthil et al. 2013). Mutations in the mouse Mip gene have also been linked to genetic cataracts, such as Fraser (Cat ${ }^{F}$ ), lens opacity (lop), Hfi, Tohm and Nat (Shiels et al. 2000, Sidjanin et al. 2001, Okamura et al. 2003, Takahashi et al. 2017). The loss of water permeability in mip-deficient mice (Shiels et al. 2001) can be rescued by the expression of AQP1 (Kumari et al. 2011). However, this does not restore the ordered packing of the lens fiber cells and still results in the formation of cataracts, confirming that MIP has unique functions in the lens that are not complemented by other aquaporins (Kumari et al. 2011).

Although mutations affecting MIP have been shown to cause cataracts in humans and mice, analogous mutations have not been reported in the giant panda (Ailuropoda melanoleuca). These animals also tend to develop cataracts in captivity because they live much longer than their counterparts in the wild, and they may therefore be exposed to additional risk factors. This phenomenon has been observed in companion animals: for example, cataract development in dogs is often associated with diabetes, obesity, prolonged use of corticosteroid, excessive exposure to sunlight, or previous eye injury/inflammation. It is therefore unclear whether cataracts in captive pandas are age-related acquired or congenital lesions due to the absence of suitable genetic markers (You et al. 2019).

Here we used a functional candidate gene screening approach to test 11 known cataract-associated genes in giant panda specimens with and without cataracts. We identified and characterized a novel 
missense mutation in the MIP gene of a female panda diagnosed with progressive cortical punctate cataracts. The mutation was not present in 18 healthy controls. The identification of this mutation will help to determine the prevalence of congenital cataracts in pandas, and will provide a new diagnostic tool for cataract risk assessment in the zoo environment.

\section{Results}

\section{Clinical findings}

The proband in this study was Jini, a giant panda born in 1993. Mild cataract symptoms were first observed in 2013, and in 2017 the lesion was diagnosed as a unilateral senile (age-related) cataract following a professional examination by an ophthalmologist (Figure 1). However, in the absence of genetic data it was not possible to confirm whether the cataract was acquired or congenital. The ophthalmologist's diagnosis represented the transition from initial cataract formation to the immature stage of a cortical cataract, and accordingly the pupil area was not occluded and there was only slight visual impairment. In this condition, the cortex absorbs water and swells, the lens volume increases, and the anterior chamber becomes shallow, accompanied by mild secondary glaucoma. Jini's case records indicated no history of eye trauma or other diseases. We therefore selected Jini for genetic analysis in order to screen for genetic markers that can be used to differentiate between congenital and acquired cataracts. We selected 18 controls without cataracts, including all traceable relatives of Jini and unrelated controls from diverse geographical locations within China (Table 2). This was necessary to distinguish disease-associated mutations from irrelevant single-nucleotide polymorphisms (SNPs).

\section{Mutation detection}

Genomic DNA extracted from Jini and the 18 healthy controls was screened for mutations in 11 candidate genes often associated with cataracts in humans (CRYAB, CRYBA1, CRYBB1, CRYGC, HSPB6, $H S P B 7, H S P B 9, G J A 3, A Q P 3, M I P$ and HSF4). This revealed a novel missense mutation in exon 4 of the MIP gene (c.686G>A) in Jini but in none of the controls. The transition causes the replacement of a serine residue with arginine at position 229 (p.S229N) in the intracellular C-terminal tail of the protein (Figure 2). We found that Jini is heterozygous for this mutation.

\section{Structural analysis}

The amino acid sequences of human, bovine, rat, mouse and panda MIP were aligned, revealing broad conservation throughout the sequence and almost complete conservation in the 10 residues either side of the mutation site, with the only substitutions involving chemically near-identical isoleucine and valine residues (Figure 3a). The replacement of serine with asparagine within this region therefore swaps a small polar side chain for another that is chemically similar but physically larger, with the potential to form additional hydrogen bonds. ProtScale analysis confirmed that the corresponding mutation in the human MIP protein (p.S229N) would cause a decrease in overall hydrophobicity (Figure 3b). The 
potential damaging effect of p.S229N was also predicted by PROVEAN analysis, which generated a score of -0.805 , indicating a neutral mutation.

Structural predictions in SWISS-MODEL showed that the path of the MIP polypeptide backbone is altered by the mutation due to the addition of two hydrogen bonds, increasing the attraction between residue 229 and nearby amino acids (Figure 4). Following sequence alignment using Clustal $X$ v2.0, the impact of the mutation on protein structure was predicted using Modeller v9.22 with the sheep (Ovis aries) MIP (PDB: 2B60) as a template, revealing discrete changes on the protein surface (Figure 5a). As shown in Figure 5b, Ser229 in wild-type MIP forms a hydrogen bond with Ser231, whereas Asn229 in the mutant forms two weak hydrogen bonds with Ser231 and Glu232. These subtle changes in the surface properties and intramolecular interactions are likely to influence the behavior of the C-terminal tail of panda MIP and thus promote the formation of cataracts.

\section{Discussion}

Cataracts can be caused by mutations that affect the activity of several groups of lens proteins, including developmental regulators, transcription factors, lens crystallins, cytoskeletal proteins, gap junction proteins and membrane channels (Spector, 1995; Hejtmancik, 1998). The best example of the latter is MIP, an aquaporin that not only facilitates the intercellular transport of water and small solutes (Borgina et al. 1999), but also binds lens fiber cells together and ensures their optimal spacing, which is necessary for normal lens refraction behavior (Kumari \& Varadaraj 2009). At least 19 mutations in the human MIP gene are associated with congenital cataracts, 11 of which are missense mutations, as well as two nonsense mutations, two frameshifts, two splice-site mutations, and one initiation codon mutation (Table 1). Here we identified the first MIP mutation associated with cataracts in the giant panda. It is a missense mutation in exon 4 (p.S229N) that replaces a highly-conserved serine residue with arginine in the intracellular C-terminal tail of the protein. This mutation was found in Jini (identified as S1 in Table 2) but not in 18 healthy controls representing all Jini's traceable relatives as well as unrelated pandas from geographically diverse regions of China, supporting our hypothesis that p.S229N is a genuine diseaseassociated mutation and not an unrelated SNP. Jini's father (S8) was sampled and did not carry the mutation, but no samples were available from Jini's mother (who died in 2006) or Jini's five offspring (two of whom have died, whereas one was exported to a foreign zoo). More distant relatives were also traced, including a female sibling of Jini's parents who was also diagnosed with cataracts, but no samples were available. We also sampled the father (S11) and grandfather (S4) of Jini's offspring and found no mutation. In the absence of informative pedigree-related samples, we acquired samples from pandas in Beijing, Baoxing, Ya'an, Wolong and Chengdu to ensure we captured broad genetic diversity.

Like other aquaporins, MIP features six transmembrane domains $(\mathrm{H} 1-\mathrm{H} 6)$, three extracellular loops $(\mathrm{A}, \mathrm{C}$ and $\mathrm{E}$ ), and two intracellular loops ( $\mathrm{B}$ and $\mathrm{D}$ ), as well as intracellular $\mathrm{N}$ and $\mathrm{C}$ termini (Figure 2) (Chepelinsky, 2009). The C-terminal segment of the native protein is 44 amino acids in length (residues 220-263) and features an a-helix (residues 230-238) with an overlapping calmodulin-binding domain (residues 223-235) (Louis et al., 1990; Girsch et al., 1991) that regulates the permeability of the MIP 
water channels in response to $\mathrm{Ca}^{2+}$ (Nemeth-Cahalan \& Hall 2000; Nemeth-Cahalan et al. 2004). The Cterminal segment of MIP interacts not only with calmodulin, but also with the cytoskeletal protein filensin and the gap junction protein connexin 50 (Yu et al., 2005, Lindsey et al., 2006; Rose et al., 2008). The novel mutation we identified lies within the calmodulin-binding domain at the $\mathrm{N}$-terminal border of the ahelix, suggesting that the mutation may affect the permeability of MIP either constitutively or in response to $\mathrm{Ca}^{2+}$, or may disrupt its interaction with gap junctions and the cytoskeleton.

Several missense mutations associated with cataracts have been traced to exon 4 of the human MIP gene, but only one of these maps to the calmodulin-binding domain of the C-terminal segment, namely the R233K mutation identified by Lin et al. (2007). R233K is distal to our novel S229N mutation and lies within the a-helix as well as the calmodulin-binding domain, but like our mutation it replaces one residue with a chemically similar one, in this case the positively charged arginine to lysine, resulting in an autosomal dominant polymorphic binocular cataract. The S229N mutation in panda may have a similar effect, although we are unable to determine whether the cataract is polymorphic without other affected individuals (the Chinese family carrying the R233K mutation spanned six generations, with a wealth of clinical data). The presence of the cataract in Jini also suggests that the mutation is pathogenic and transmitted in an autosomal dominant manner, but both of Jini's parents were apparently healthy and her father did not carry the mutation. We can only speculate that Jini represents a new germline mutation or that her mother was an unaffected carrier due to a lack of penetrance or expressivity, the latter being relatively common for congenital cataracts in human pedigrees (Francis et al. 2000a).

Other mutations are known to truncate the C-terminal segment of MIP, which interferes with its trafficking to the plasma membrane and thus reduces or abolishes its activity (Ball et al., 2003). The C-terminal regions spanning residues 223-234 and 235-263 are critical for protein transport from the cytoplasm to the plasma membrane (Varadaraj et al., 2008; Sindhu et al., 2014) and residue Ser235 is particularly important for MIP translocation to the plasma membrane following PKC-dependent phosphorylation (Golestaneh et al., 2008). Therefore, mutant versions of MIP lacking these residues become trapped in the cytoplasm, which restricts the formation of water channels in the plasma membrane and thus reduces lens fiber cell permeability and transparency. A long-terminal repeat inserted at the $\mathrm{C}$-terminus of the mouse MIP protein was shown to disrupt lens fiber cell architecture in the Cat ${ }^{F r}$ mutant, indicating that the $\mathrm{C}$-terminal segment is also required for the development of the correct cellular architecture in the crystalline lens (Shiels et al, 1996; 2000; Kalman et al., 2006).

Part of the C-terminus is cleaved from MIP post-translationally such that mature lens fiber cells accumulate a truncated derivative (residues 1-246) rather than the full-length 263-residue protein. In transgenic knockout mice lacking a functional Mip gene, knocking in the C-terminal truncated sequence (making it the only version of MIP available throughout development) did not prevent the lens becoming opaque, and water permeability was reduced, but cell-cell adhesion was stronger than in the wild-type cells (Sindhu et al., 2019). These results confirmed that full-length MIP is required for normal permeability although the truncated version does function as a water channel, and can be explained by the requirement of the complete $\mathrm{C}$-terminal segment to traffic MIP to the plasma membrane. The truncation 
clearly plays an important role in cell-cell adhesion, which is enhanced when only the truncated MIP is available. The presence of our novel S229N mutation in this region of the panda MIP sequence indicates that the predicted structural alterations are likely to affect the structure and transparency of the lens by interfering with both permeability and cell-cell interactions. Our data provide more evidence of the pathogenic mechanisms of cataract formation in panda and extend the spectrum of known MIP gene mutations.

\section{Methods}

\section{Proband and controls}

Jini is a female giant panda who was born in 1993 in Beijing Zoo (China). Her mother was born in wild in 1981 and her father was born in Beijing Zoo in 1986. Both parents were healthy. Jini underwent examination at 28 years of age and was first diagnosed with senile cataract, but now also shows signs of corneal atrophy. She has poor vision and slow movement but no history of related systemic abnormalities. In addition to Jini (S1), we selected 18 healthy captive giant panda samples as controls, including Jini's father (S8) and the father (S11) and grandfather (S4) of Jini's offspring. The other samples (unrelated to Jini) were collected from pandas in Beijing, Baoxing, Ya'an, Wolong and Chengdu (Table 2).

\section{Mutation detection}

We selected 11 candidate genes that are often associated with cataracts in humans (CRYAB, CRYBA1, CRYBB1, CRYGC, HSPB6, HSPB7, HSPB9, GJA3, AQP3, MIP and HSF4) and used them as functional candidates for mutation analysis in Jini and the controls. Peripheral venous blood samples $(2 \mathrm{ml})$ were collected and stored at $-80^{\circ} \mathrm{C}$. Genomic DNA was extracted with phenol/chloroform (SigmaAldrich/Merck Millipore, Shanghai, China) immediately before analysis. Blood samples were collected in accordance with the Wildlife Protection Law of the People's Republic of China (President of the People's Republic of China No. 16), and the experimental approach was approved by the Beijing Zoo Academic and Ethics Committee.

PCR was carried out using the exon-spanning primers listed in Table S1. Each $25-\mu$ l reaction comprised $1.5 \mathrm{mM} \mathrm{MgCl}_{2}, 0.2 \mathrm{mM}$ dNTPs, $0.5 \mu \mathrm{M}$ of the appropriate forward and reverse primers, $2.5 \mathrm{U}$ Taq DNA polymerase (TianGen, Beijing, China) and 20 ng genomic DNA in 1x PCR buffer (TianGen, Beijing, China). The samples were denatured at $95^{\circ} \mathrm{C}$ for $5 \mathrm{~min}$, followed by 34 cycles of $95^{\circ} \mathrm{C}$ for $30 \mathrm{~s}, 57-63^{\circ} \mathrm{C}$ (depending on the primer pair) for $30 \mathrm{~s}$, and $72^{\circ} \mathrm{C}$ for $30 \mathrm{~s}$, and a final extension step at $72{ }^{\circ} \mathrm{C}$ for $10 \mathrm{~min}$. The products were sequenced using an ABI 3730 Automated Sequencer (PE Biosystems, Foster City, CA, USA), analyzed using Chromas v2.33 and compared to the reference sequence in the NCBI database (Li et al. 2010). The sequence of the mutated giant panda MIP gene has been deposited in the NCBI GenBank database under accession number MT447398. 
MIP amino acid sequences from five different species (human, bovine, rat, mouse and panda) were aligned and analyzed using CLC Free Workbench v4.5.1 (CLC Bio, Aarhus, Denmark). Protein hydrophilicity was determined using ProtScale (Gasteiger et al., 2005). The effects of the predicted amino acid substitution on the structure of MIP, and interactions between amino acid side chains, were predicted using SWISS-MODEL (Schwede et al. 2003; Bienert et al. 2017), THREADER v3.5 (Jones et al., 1992; 1995), Modeller v9.22 (Sali and Blundell, 1993) and were visualized using Discovery Studio Visualizer. The damaging effects of the mutation were predicted using PROVEAN v1.1.3 (http://provean.jcvi.org/index.php).

\section{Declarations}

\section{Ethics approval and consent to participate}

Blood samples were collected in accordance with the Wildlife Protection Law of the People's Republic of China (President of the People's Republic of China No. 16), and the experimental approach was approved by the Beijing Zoo Academic and Ethics Committee.

\section{Consent for publication}

Not applicable.

\section{Availability of data and materials}

Table S1 reports PCR primers designed for screening the candidate gene mutants.

The sequencing data are publicly available at NCBI GenBank (accession number MT447398). All data necessary for confirming the conclusions of the article are present within the article, figures, and tables.Competing interests

The authors declare no conflict of interest.

\section{Funding}

This study was supported by the National Natural Science Foundation of China (NSFC 31872257).

\section{Author Contributions}

Chao Bai: writing draft article, data collection and analysis. Yuyan You: conceptualization, funding acquisition, writing draft article, data collection and analysis. Resources: Xuefeng Liu, Maohua Xia, Yucun Chen, Wei Wang, Ting Jia, Chenglin Zhang, Xiaoguang Li, Liqin Wang, Yanqiang Yin, Yunfang Xiu, Lili Niu, Jun Zhou, Yang Du, Yanhui Liu.

\section{Acknowledgements}


The authors acknowledge the support of the Strait (Fuzhou) Giant Panda Research and Exchange Centers.

\section{References}

Arora A, Minogue PJ, Liu X, Addison PK, Russel-Eggitt I, Webster AR, Hunt DM, Ebihara L, Beyer EC, Berthoud VM, Moore AT. A novel connexin50 mutation associated with congenital nuclear pulverulent cataracts. J Med Genet 2008; 45:155-6.

Ball LE, Little M, Nowak MW, Garland DL, Crouch RK, Schey KL. Water permeability of C-terminally truncated aquaporin 0 (AQP0 1-243) observed in the aging human lens. Invest Ophthalmol Vis Sci 2003; 44:4820-8.

Bassnett S, Wilmarth PA, David LL. The membrane proteome of the mouse lens fiber cell. Mol Vis. 2009;15:2448-63.

Berry V, Francis P, Kaushal S, Moore A, Bhattacharya S. Missense mutations in MIP underlie autosomal dominant 'polymorphic' and lamellar cataracts linked to 12q. Nat Genet 2000; 25:15-7.

Bienert S, Waterhouse A, de Beer TA, Tauriello G, Studer G, Bordoli L, Schwede T. The SWISS-MODEL Repository-new features and functionality. Nucleic Acids Res 2017; 45:D313-9.

Borgnia M, Nielsen S, Engel A, Agre P. Cellular and molecular biology of the aquaporin water channels. Annu Rev Biochem1999; 68:425-58.

Bu L, Jin Y, Shi Y, Chu R, Ban A, Eiberg H, Andres L, Jiang H, Zheng G, Qian M, Cui B, Xia Y, Liu J, Hu L, Zhao G, Hayden MR, Kong X. Mutant DNA-binding domain of HSF4 is associated with autosomal dominant lamellar and Marner cataract. Nat Genet 2002; 31:276-8.

Burdon KP, Wirth MG, Mackey DA, Russell-Eggitt IM, Craig JE, Elder JE, Dickinson JL, Sale MM. A novel mutation in the Connexin 46 gene causes autosomal dominant congenital cataract with incomplete penetrance. J Med Genet 2004; 41:e106.

Chepelinsky AB. Structural function of MIP/aquaporin 0 in the eye lens; genetic defects lead to congenital inherited cataracts. Handb Exp Pharmacol. 2009; (190):265-97.

Chepelinsky AB. The ocular lens fiber membrane specific protein MIP/Aquaporin 0. J Exp Zool A Comp Exp Biol 2003; 300:41-6.

Conley YP, Erturk D, Keverline A, Mah TS, Keravala A, Barnes LR, Bruchis A, Hess JF, FitzGerald PG, Weeks DE, Ferrell RE, Gorin MB. A juvenile-onset, progressive cataract locus on chromosome 3q21-q22 is associated with a missense mutation in the beaded filament structural protein-2. Am J Hum Genet 2000; 66:1426-31. 
Ding X, Zhou N, Lin H, Chen J, Zhao C, Zhou G, Hejtmancik JF, Qi Y. A novel MIP gene mutation analysis in a Chinese family affected with congenital progressive punctate cataract. PLoS One 2014; 9:e102733.

Francis P, Chung JJ, Yasui M, Berry V, Moore A, Wyatt MK, Wistow G, Bhattacharya SS, Agre P.. Functional impairment of lens aquaporin in two families with dominantly inherited cataracts. Hum Mol Genet 2000b; 9:2329-34.

Francis PJ, Berry V, Bhattacharya SS, Moore AT. Genetics of childhood cataract. J Med Genet 2000a; 37:481-8.

Gasteiger E, Hoogland C, Gattiker A, Duvaud S, Wilkins MR, Appel RD, Bairoch A. Protein Identification and Analysis Tools on the ExPASy Server. Walker JM (ed) The Proteomics Protocols Handbook. Humana Press, Totowa, NJ, USA, 2005, pp. 571-607.

Geyer DD, Spence MA, Johannes M, Flodman P, Clancy KP, Berry R, Sparkes RS, Jonsen MD, Isenberg SJ, Bateman JB. Novel single-base deletional mutation in major intrinsic protein (MIP) in autosomal dominant cataract. Am J Ophthalmol. 2006; 141:761-3.

Girsch SJ, Peracchia C. Calmodulin interacts with a C-terminus peptide from the lens membrane protein MIP26. Curr Eye Res 1991; 10:839-49.

Golestaneh N, Fan J, Zelenka P, Chepelinsky AB. PKC putative phosphorylation site Ser235 is required for MIP/AQP0 translocation to the plasma membrane. Mol Vis 2008; 14:1006-14.

Gu F, Zhai H, Li D, Zhao L, Li C, Huang S, Ma X. A novel mutation in major intrinsic protein of the lens gene (MIP) underlies autosomal dominant cataract in a Chinese family. Mol Vis 2007; 13:1651-6.

Hejtmancik JF. The genetics of cataract: our vision becomes clearer. Am J Hum Genet 1998; 62:520-5.

Jakobs PM, Hess JF, FitzGerald PG, Kramer P, Weleber RG, Litt M. Autosomal-dominant congenital cataract associated with a deletion mutation in the human beaded filament protein gene BFSP2. Am J Hum Genet 2000; 66:1432-6.

Jiang B, Chen Y, Xu B, Hong N, Liu R, Qi M, Shen L. Identification of a novel missense mutation of MIP in a Chinese family with congenital cataracts by target region capture sequencing. Sci Rep 2017; 7:40129

Jiang J, Jin C, Wang W, Tang X, Shentu X, Wu R, Wang Y, Xia K, Yao K. Identification of a novel splice-site mutation in MIP in a Chinese congenital cataract family. Mol Vis 2009; 15:38-44.

Jones DT, Miller RT, Thornton JM. Successful protein fold recognition by optimal sequence threading validated by rigorous blind testing. Proteins 1995;23:38797.

Jones DT, Taylor WR, Thornton JM. A new approach to protein fold recognition. Nature 1992; 358:86-9. 
Kalman K, Nemeth-Cahalan KL, Froger A, Hall JE. AQPO- LTR of the Cat Fr mouse alters water permeability and calcium regulation of wild type AQP0. Biochim Biophys Acta 2006; 1758:1094-9.

Kumari SS, Eswaramoorthy S, Mathias RT, Varadaraj K. Unique and analogous functions of aquaporin 0 for fiber cell architecture and ocular lens transparency. Biochim Biophys Acta 2011; 1812:1089-97.

Kumari SS, Varadaraj K. Intact AQP0 performs cell-to-cell adhesion. Biochem Biophys Res Commun 2009; 390:1034-9.

Li R, Fan W, Tian G, Zhu H, He L, Cai J, Huang Q, Cai Q, Li B, Bai Y, et al. The sequence and de novo assembly of the giant panda genome. Nature 2010;63:311-7.

Lin H, Hejtmancik JF, Qi Y. A substitution of arginine to lysine at the $\mathrm{COOH}$-terminus of MIP caused a different binocular phenotype in a congenital cataract family. Mol Vis 2007; 13:1822-7.

Lindsey Rose KM, Gourdie RG, Prescott AR, Quinlan RA, Crouch RK, Schey KL. The C-terminus of lens aquaporin 0 interacts with the cytoskeletal proteins filensin and CP49. Invest Ophthalmol Vis Sci 2006; 47:1562-70.

Litt M, Carrero-Valenzuela R, LaMorticella DM, Schultz DW, Mitchell TN, Kramer P, Maumenee IH. Autosomal dominant cerulean cataract is associated with a chain termination mutation in the human beta-crystallin gene CRYBB2. Hum Mol Genet 1997; 6:665-8.

Liu BF, Liang JJ. Confocal fluorescence microscopy study of interaction between lens MIP26/AQP0 and crystallins in living cells. J Cell Biochem 2008; 104:51-8.

Liu J, Xu J, Gu S, Nicholson BJ, Jiang JX. Aquaporin 0 enhances gap junction coupling via its cell adhesion function and interaction with connexin 50. J Cell Sci. 2011; 124:198-206.

Long X, Huang Y, Tan H, Li Z, Zhang R, Linpeng S, Lv W, Cao Y, Li H, Liang D, Wu L. Identification of a novel MIP frameshift mutation associated with congenital cataract in a Chinese family by whole-exome sequencing and functional analysis. Eye (Lond) 2018; 32:1359-64.

Louis CF, Hogan P, Visco L, Strasburg G. Identity of the calmodulin-binding proteins in bovine lens plasma membranes. Exp Eye Res 1990; 50:495-503.

Lu S, Zhao C, Jiao H, Kere J, Tang X, Zhao F, Zhang X, Zhao K, Larsson C. Two Chinese families with pulverulent congenital cataracts and deltaG91 CRYBA1 mutations. Mol Vis 2007; 13:1154-60.

Mathias RT, Kistler J, Donaldson P. The lens circulation. J Membr Biol 2007; 216:1-16.

Meyer E, Rahman F, Owens J, Pasha S, Morgan NV, Trembath RC, Stone EM, Moore AT, Maher ER. Initiation codon mutation in betaB1-crystallin (CRYBB1) associated with autosomal recessive nuclear pulverulent cataract. Mol Vis 2009; 15:1014-9. 
Nemeth-Cahalan KL, Hall JE. pH and calcium regulate the water permeability of aquaporin 0. J Biol Chem $2000 ; 275: 6777-82$.

Nemeth-Cahalan KL, Kalman K, Hall JE. Molecular basis of $\mathrm{pH}$ and $\mathrm{Ca}^{2+}$ regulation of aquaporin water permeability. J Gen Physiol 2004; 123:573-80.

Okamura T, Miyoshi I, Takahashi K, Mototani Y, Ishigaki S, Kon Y, Kasai N. Bilateral congenital cataracts result from a gain-of-function mutation in the gene for aquaporin-0 in mice. Genomics 2003 81:361-8.

Qin L, Guo L, Wang H, Li T, Lou G, Guo Q, Hou Q, Liu H, Liao S, Liu Z. A novel MIP mutation in familial congenital nuclear cataracts. Eur J Med Genet 2016; 59:488-91.

Rose KM, Wang Z, Magrath GN, Hazard ES, Hildebrandt JD, Schey KL. Aquaporin 0-calmodulin interaction and the effect of aquaporin 0 phosphorylation. Biochemistry 2008; 47:339-47.

Sali A, Blundell TL. Comparative protein modelling by satisfaction of spatial restraints. J Mol Biol 1993; 234:779-815.

Schwede T, Kopp J, Guex N, Peitsch MC. SWISS-MODEL: an automated protein homology-modeling server. Nucleic Acids Res 2003; 31:3381-5.

Semina EV, Ferrell RE, Mintz-Hittner HA, Bitoun P, Alward WL, Reiter RS, Funkhauser C, Daack-Hirsch S, Murray JC. A novel homeobox gene PITX3 is mutated in families with autosomal-dominant cataracts and ASMD. Nat Genet 1998; 19:167-70.

Senthil Kumar G, Kyle JW, Minogue PJ, Dinesh Kumar K, Vasantha K, Berthoud VM, Beyer EC, Santhiya ST. An MIP/AQPO mutation with impaired trafficking and function underlies an autosomal dominant congenital lamellar cataract. Exp Eye Res 2013; 110:136-41.

Shentu X, Miao Q, Tang X, Yin H, Zhao Y. Identification and functional analysis of a novel MIP gene mutation associated with congenital cataract in a Chinese family. PLoS One 2015; 10:e0126679.

Shiels A, Bassnett S, Varadaraj K, Mathias R, Al-Ghoul K, Kuszak J, Donoviel D, Lilleberg S, Friedrich G, Zambrowicz B. Optical dysfunction of the crystalline lens in aquaporin-0-deficient mice. Physiol Genomics 2001; 7:179-86.

Shiels A, Bassnett S. Mutations in the founder of the MIP gene family underlie cataract development in the mouse. Nat Genet 1996; 12:212-5.

Shiels A, Mackay D, Bassnett S, Al-Ghoul K, Kuszak J. Disruption of lens fiber cell architecture in mice expressing a chimeric AQP0-LTR protein. FASEB J 2000; 14:2207-12.

Sidjanin DJ, Parker-Wilson DM, Neuhäuser-Klaus A, Pretsch W, Favor J, Deen PM, Ohtaka-Maruyama C, Lu Y, Bragin A, Skach WR, Chepelinsky AB, Grimes PA, Stambolian DE. A 76-bp deletion in the Mip gene 
causes autosomal dominant cataract in Hfi mice. Genomics 2001;74:313-9.

Sindhu KS, Varadaraj K. A predominant form of C-terminally end-cleaved AQPO functions as an open water channel and an adhesion protein in AQPODC/DC mouse lens. Biochem Biophys Res Commun 2019; 511:626-30.

Sindhu KS, Varadaraj K. Intact and N- or C-terminal end truncated AQPO function as open water channels and cell-to-cell adhesion proteins: end truncation could be a prelude for adjusting the refractive index of the lens to prevent spherical aberration. Biochim Biophys Acta 2014; 1840:2862-77.

Song Z, Wang L, Liu Y, Xiao W. A novel nonsense mutation in the MIP gene linked to congenital posterior polar cataracts in a Chinese family. PLoS One 2015; 10:e0119296.

Spector, A. Oxidative stress-induced cataract: mechanism of action. FASEB J 1995; 9:1173-82.

Takahashi G, Hasegawa S, Fukutomi Y, Harada C, Furugori M, Seki Y, Kikkawa Y, Wada K. A novel missense mutation of Mip causes semi-dominant cataracts in the Nat mouse. Exp Animals 2017; 66:27182.

Vanita V, Singh JR, Hejtmancik JF, Nuernberg P, Hennies HC, Singh D, Sperling K. A novel fan-shaped cataractmicrocornea syndrome caused by a mutation of CRYAA in an Indian family. Mol Vis 2006; $12: 518-22$.

Varadaraj K, Kumari SS, Patil R, Wax MB, Mathias RT. Functional characterization of a human aquaporin 0 mutation that leads to a congenital dominant lens cataract. Exp Eye Res 2008; 87:9-21.

Wang KJ, Li SS, Yun B, Ma WX, Jiang TG, Zhu SQ. A novel mutation in MIP associated with congenital nuclear cataract in a Chinese family. Mol Vis 2011; 17:70-7.

Wang W, Jiang J, Zhu Y, Li J, Jin C, Shentu X, Yao K. A novel mutation in the major intrinsic protein (MIP) associated with autosomal dominant congenital cataracts in a Chinese family. Mol Vis 2010; 16:534-9.

Xiao X, Li W, Wang P, Li L, Li S, JiaX, Sun W, Guo X, Zhang Q. Cerulean cataract mapped to 12q13 and associated with a novel initiation codon mutation in MIP. Mol Vis 2011; 17:2049-55.

Yang G, Zhang G, Wu Q, Zhao J.. A novel mutation in the MIP gene is associated with autosomal dominant congenital nuclear cataract in a Chinese family. Mol Vis 2011; 17:1320-3.

Yao K, Jin C, Zhu N, Wang W, Wu R, Jiang J, Shentu X. A nonsense mutation in CRYGC associated with autosomal dominant congenital nuclear cataract in a Chinese family. Mol Vis 2008; 14:1272-6.

You Y, Bai C, Liu X, Xia M, Jia T, Li X, Zhang C, Chen Y, Zhao S, Wang L, Wang W, Yin Y, Xiu Y, Niu L, Zhou J, Ma T, Du Y, Liu Y. Genome-wide analysis of methylation in giant pandas with cataract by methylationdependent restriction-site associated DNA sequencing (MethyIRAD). PLoS One 2019; 14:e0222292. 
Yu XS, Yin X, Lafer EM, Jiang JX. Developmental regulation of the direct interaction between the intracellular loop of connexin 45.6 and the C-terminus of major intrinsic protein (aquaporin-0). J Biol Chem 2005; 280:22081-90.

Yu Y, Yu Y, Chen P, Li J, Zhu Y, Zhai Y, Yao K. A novel MIP gene mutation associated with autosomal dominant congenital cataracts in a Chinese family. BMC Med Genet 2014; 15:6.

Zeng L, Liu W, Feng W, Wang X, Dang H, Gao L, Yao J, Zhang X. A novel donor splice-site mutation of major intrinsic protein gene associated with congenital cataract in a Chinese family. Mol Vis 2013; 19:2244-9.

Zhang LY, Yam GH, Fan DS, Tam PO, Lam DS, Pang CP. A novel deletion variant of gamma D-crystallin responsible for congenital nuclear cataract. Mol Vis 2007; 13:2096-104.

\section{Tables}

Table 1. Known mutations in the human MIP gene compared to the novel mutation in the panda MIP gene.

Table 2. Characteristics of the proband and control specimens. 


\begin{tabular}{|c|c|c|c|c|c|c|c|}
\hline Exon/intron & DNA Change & Coding Change & Inheritance & Origin & Phenotype & Species & Reference \\
\hline Exon 1 & c. $2 \mathrm{~T}>\mathrm{C}$ & p.M1T & $\mathrm{AD}$ & China & Initiation codon mutation & Human & Xiao et al., 2011 \\
\hline \multirow[t]{3}{*}{ (p1-120) } & c. $97 \mathrm{C}>\mathrm{T}$ & p.R33C & $\mathrm{AD}$ & China & Missense & Human & Gu et al., 2007 \\
\hline & c. $319 \mathrm{G}>\mathrm{A}$ & p.V107I & $\mathrm{AD}$ & China & Missense & Human & Wang et al., 2010 \\
\hline & c. $337 \mathrm{C}>\mathrm{T}$ & p.R113* & $\mathrm{AD}$ & China & Nonsense mutation & Human & Yu et al., 2014 \\
\hline Exon 2 & c. $401 \mathrm{C}>\mathrm{G}$ & p.E134G & $\mathrm{AD}$ & UK & Missense & Human & Berry et al., 2000 \\
\hline \multirow[t]{4}{*}{ (p121-175) } & c. $413 \mathrm{C}>\mathrm{G}$ & p.T138R & $\mathrm{AD}$ & UK & Missense mutation & Human & Berry et al., 2000 \\
\hline & c. $448 \mathrm{G}>\mathrm{C}$ & p.D150H & $\mathrm{AD}$ & China & Missense & Human & Shentu et al., 2015 \\
\hline & c. $494 \mathrm{G}>\mathrm{A}$ & p.G165D & $\mathrm{AD}$ & South Indian & Missense mutation & Human & Senthilet al., 2013 \\
\hline & c.508dupC & p.L170fs & $\mathrm{AD}$ & China & Missense & Human & Qin et al., 2016 \\
\hline Exon 3 & c. $530 \mathrm{~A}>\mathrm{G}$ & P.Y177C & $\mathrm{AD}$ & China & Missense & Human & Yang et al., 2011 \\
\hline (p176-202) & c. $559 \mathrm{C}>\mathrm{T}$ & p.R187C & $\mathrm{AD}$ & China & Missense & Human & Wang et al., 2011 \\
\hline \multirow[t]{2}{*}{ Intron3 } & IVS3-1G >A & & $\mathrm{AD}$ & China & Splice-acceptor mutation & Human & Jiang et al., 2009 \\
\hline & $(\mathrm{c} .606+1 \mathrm{G}>\mathrm{A})$ & & $\mathrm{AD}$ & China & Splice-donor mutation & Human & Zeng et al., 2013 \\
\hline Exon 4 & c. $634 \mathrm{G}>\mathrm{C}$ & p.G212R & $\mathrm{AD}$ & China & Missense & Human & Jiang et al., 2017 \\
\hline \multirow[t]{5}{*}{ (p230-263) } & c.638delG & p.G213fs & $\mathrm{AD}$ & US & Frame shift mutation & Human & Geyer et al., 2006 \\
\hline & c. $644 \mathrm{G}>\mathrm{A}$ & p.G215D & $\mathrm{AD}$ & China & Missense & Human & Ding et al., 2014 \\
\hline & c. $657 \mathrm{C}>\mathrm{G}$ & p.Y219* & $\mathrm{AD}$ & China & Nonsense mutation & Human & Song et al., 2015 \\
\hline & c.682_683delAA & p.K228fs & $\mathrm{AD}$ & China & Frame shift mutation & Human & Long et al., 2018 \\
\hline & c. $702 \mathrm{G}>\mathrm{A}$ & p.R233K & $\mathrm{AD}$ & China & Missense mutation & Human & Lin et al., 2007 \\
\hline Exon 4 & $G>A$ & p.S229N & & China & Missense & Panda & This study \\
\hline
\end{tabular}




\begin{tabular}{|c|c|c|c|c|c|c|c|c|}
\hline & & $\begin{array}{l}\text { Birth } \\
\text { year }\end{array}$ & Sex & Status & Origin & Mutation & Cataracts & Comments \\
\hline 1 & $\begin{array}{l}\text { S1 } \\
\text { (proband) }\end{array}$ & 1993 & Female & Alive & Beijing & + & + & \\
\hline 2 & $\mathrm{~S} 2$ & 1996 & Female & Dead & Beijing & - & - & \\
\hline 3 & S3 & 1986 & Female & Dead & Beijing & - & - & \\
\hline 4 & $\mathrm{~S} 4$ & 1992 & Male & Alive & Beijing & - & - & $\begin{array}{l}\text { Grandfather of Jini's } \\
\text { offspring }\end{array}$ \\
\hline 5 & S5 & 1999 & Male & Alive & Beijing & - & - & \\
\hline 6 & S6 & 2013 & Male & Alive & Beijing & - & - & \\
\hline 7 & S7 & 1998 & Male & Dead & Beijing & - & - & \\
\hline 8 & S8 & 1986 & Male & Dead & Beijing & - & - & Jini's father \\
\hline 9 & S9 & & & Alive & Beijing & - & - & \\
\hline 10 & $\mathrm{~S} 10$ & 1982 & Female & Alive & Baoxing & - & - & \\
\hline 11 & $\mathrm{~S} 11$ & 1999 & Male & Alive & Baoxing & - & - & Father of Jini's offspring \\
\hline 12 & $\mathrm{~S} 12$ & 2007 & Male & Alive & Yaan & - & - & \\
\hline 13 & $\mathrm{~S} 13$ & 2009 & Male & Alive & Yaan & - & - & \\
\hline 14 & S14 & 2009 & Female & Alive & Yaan & - & - & \\
\hline 15 & S15 & 2011 & Female & Alive & Yaan & - & - & \\
\hline 16 & $\mathrm{~S} 16$ & 1998 & Female & Alive & Wolong & - & - & \\
\hline 17 & $\mathrm{~S} 17$ & & Female & Dead & Wolong & - & - & \\
\hline 18 & S18 & 2003 & Female & Alive & Wolong & - & - & \\
\hline 19 & S19 & 1989 & Female & Dead & Chengdu & - & - & \\
\hline
\end{tabular}




\section{Figures}

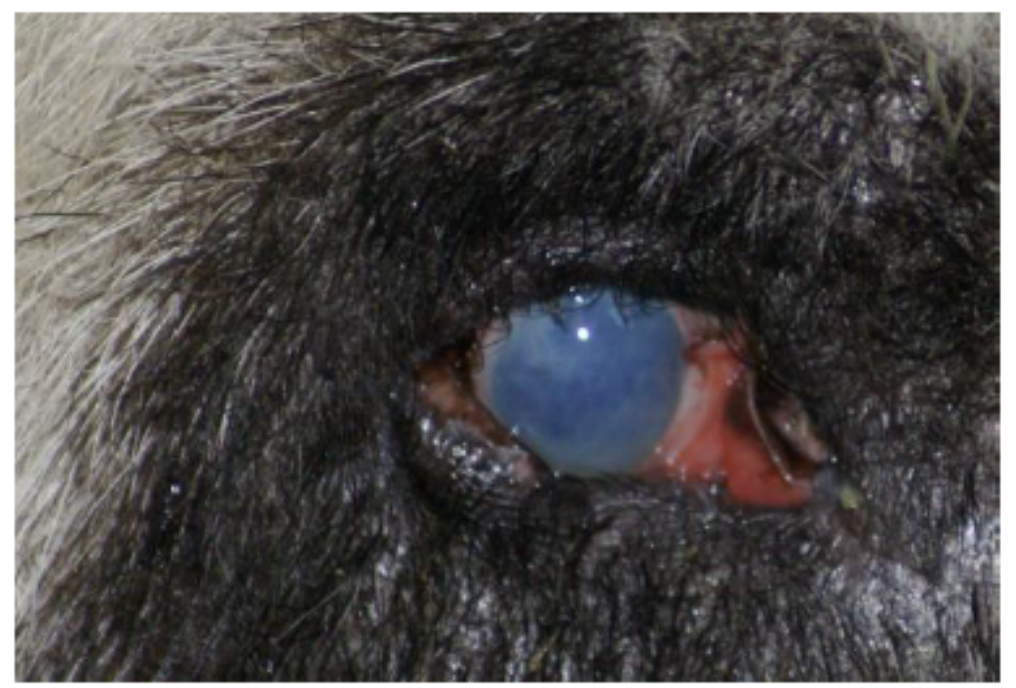

\section{Figure 1}

The right eye of Jini, a female giant panda with a senile cataract. 

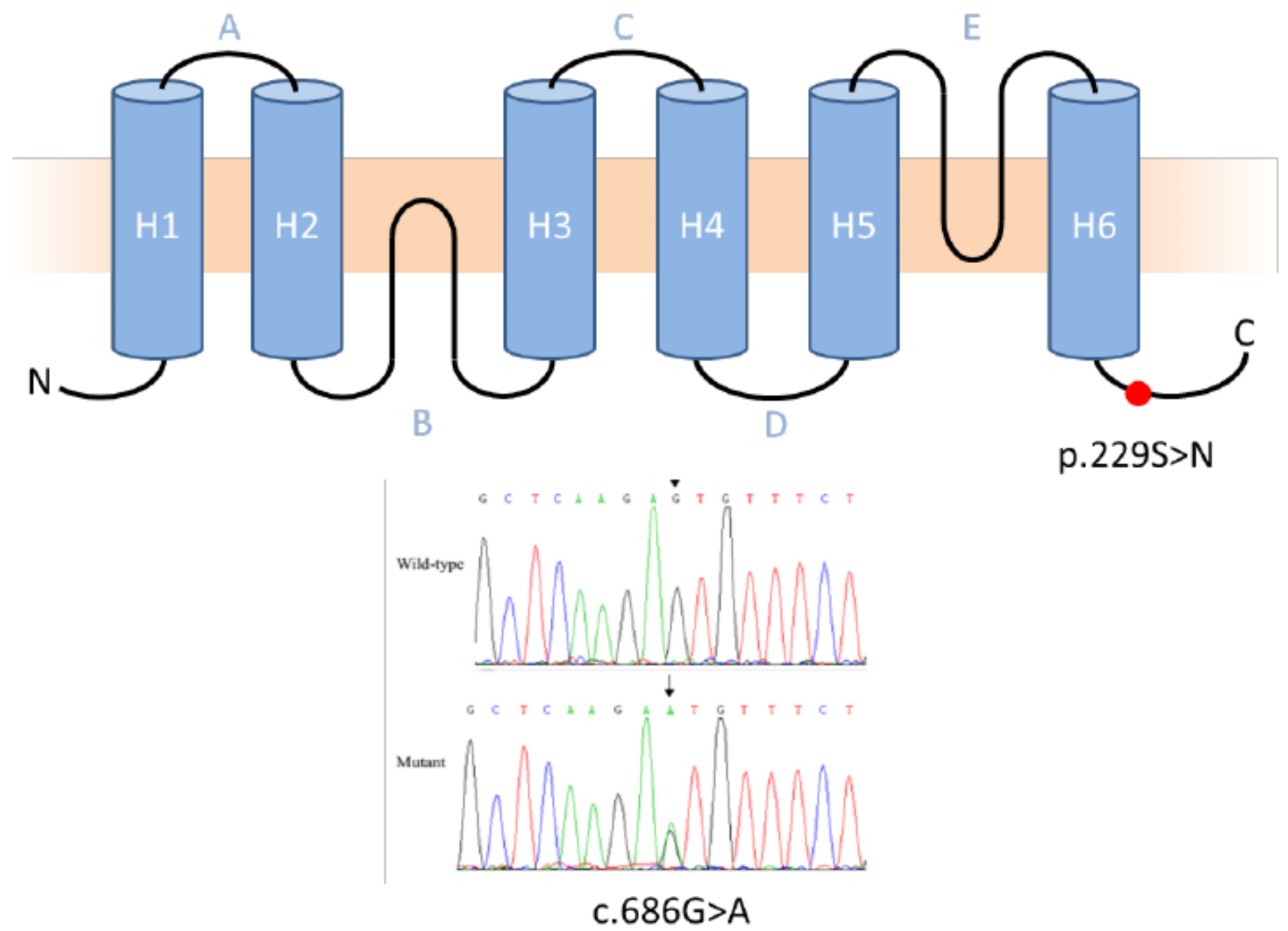

Figure 2

Location and identification of the mutation in the MIP gene of Jini. (a) Extended structure of MIP, showing the six transmembrane domains $(\mathrm{H} 1-\mathrm{H} 6)$, extracellular loops $(\mathrm{A} / \mathrm{C} / \mathrm{E})$, intracellular loops $(\mathrm{B} / \mathrm{D})$, the intracellular $\mathrm{N}$-terminal portion, and the intracellular $\mathrm{C}$-terminal tail, the latter containing the mutation site (red dot). (b) Sequence trace of the 16-bp region spanning the mutation site, comparing the six wild-type individuals (top) and Jini (bottom), revealing the heterozygous mutation (c.686G>A). 


\section{Jini YDFLLFPRLK NVSERLSILK G (239)}

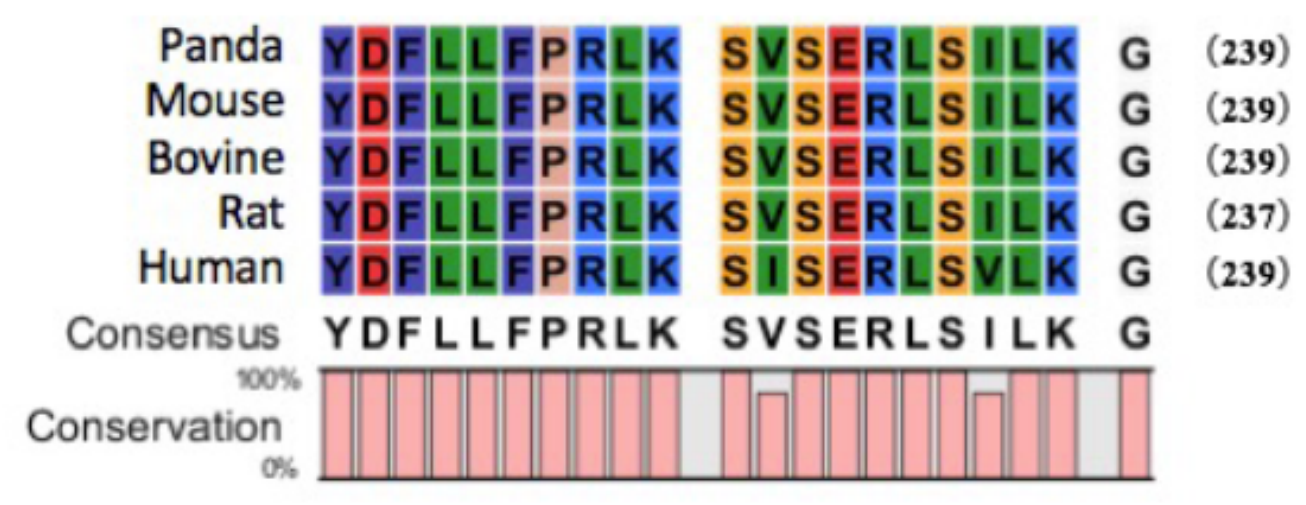

b
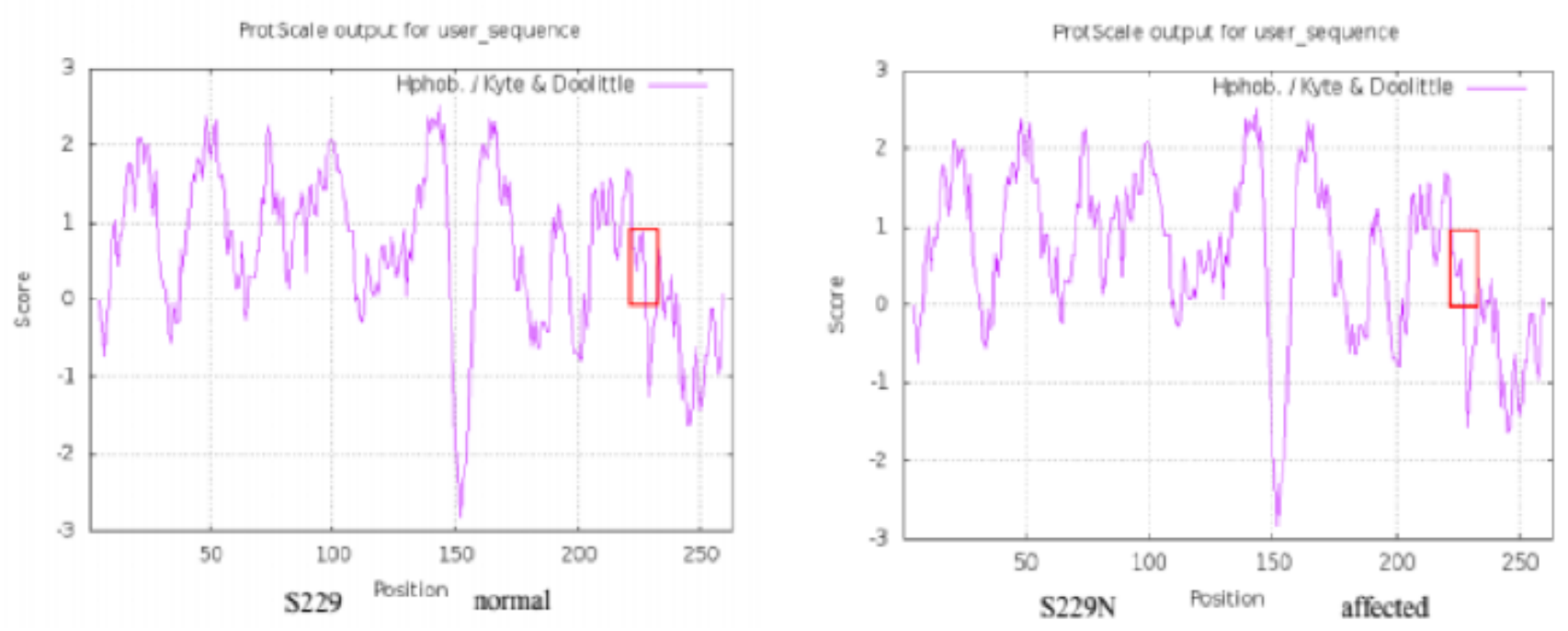

\section{Figure 3}

The S229N mutation within the intracellular C-terminal domain of MIP affects protein hydrophobicity. (a) Multiple alignment of a highly-conserved sequence of 21 amino acids in five orthologs of MIP (panda, mouse, bovine, rat and human) showing that the panda S229N substitution affects a serine residue conserved across all species. (b) ProtScale analysis of the human protein with the equivalent mutation (S229N) confirming a decrease in overall hydrophobicity. 


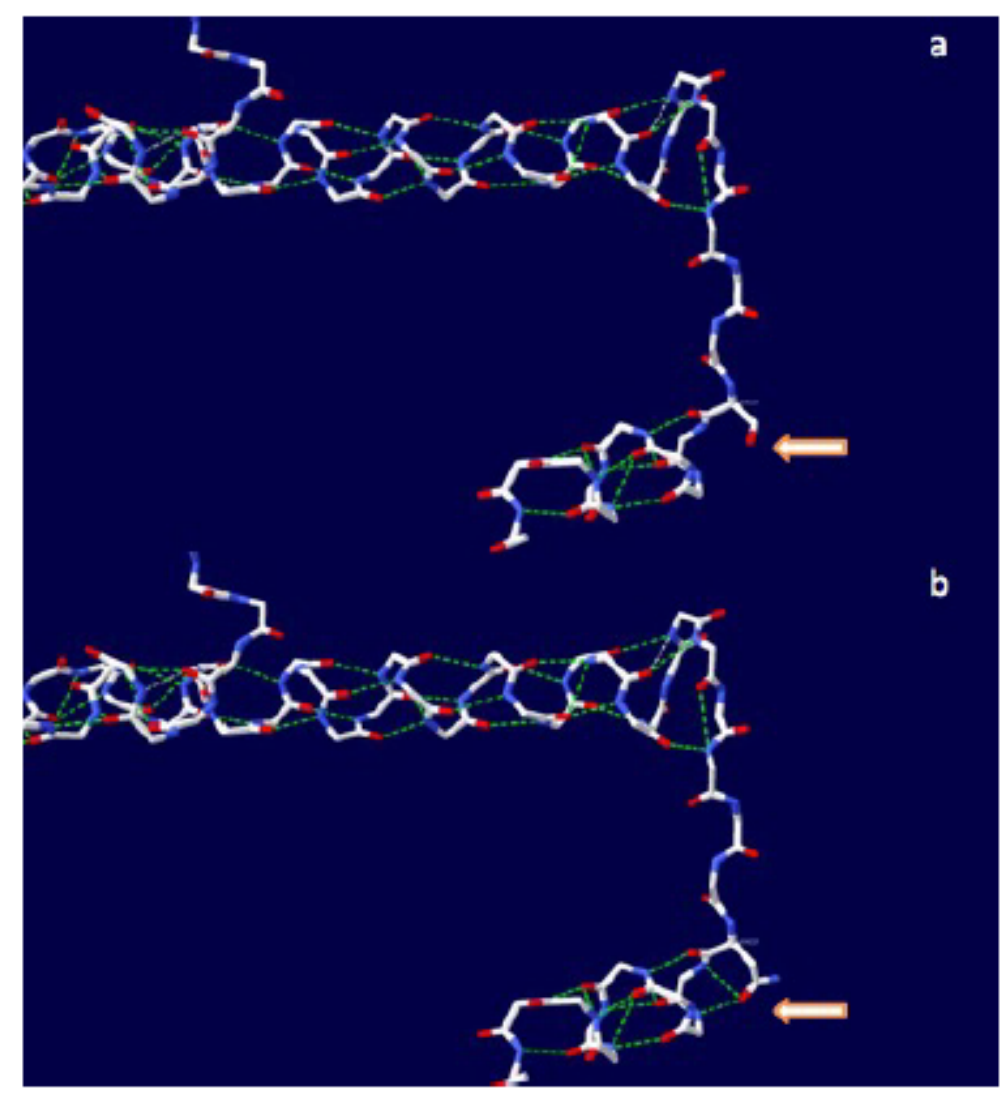

\section{Figure 4}

The path of the MIP polypeptide backbone predicted using SWISS-MODEL. (a) Model of wild-type human MIP. (b) Model of the S229N mutant. The arrows indicate the difference in intramolecular interactions between wild-type MIP and the S229N mutant, with the latter able to form two new hydrogen bonds (shown as broken green lines). 

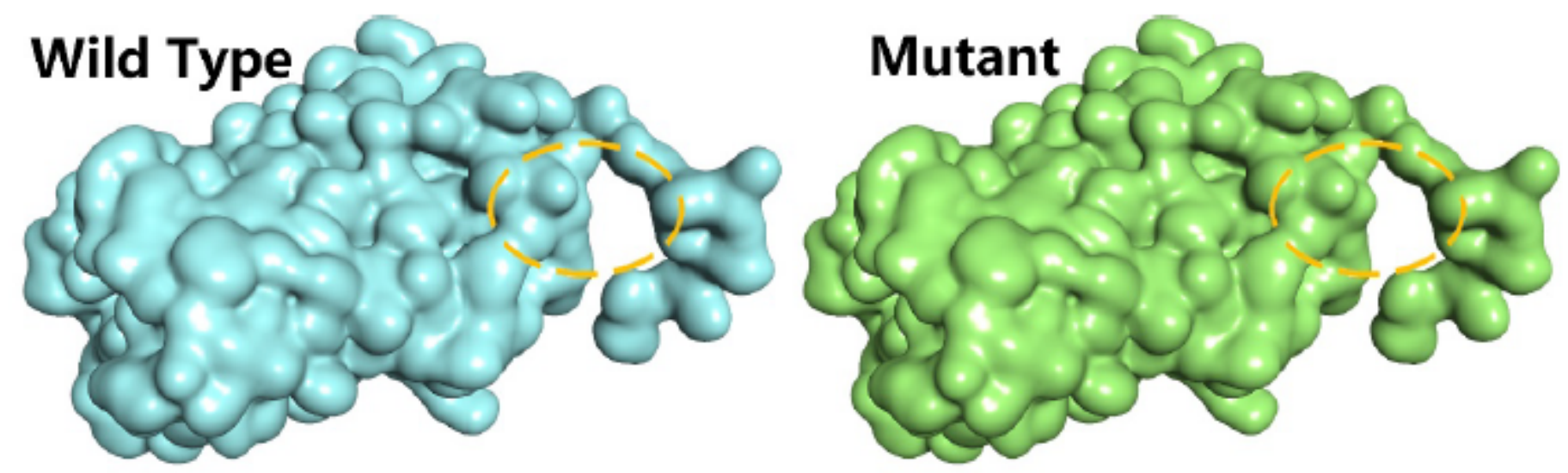

(a)

\section{Wild Type}

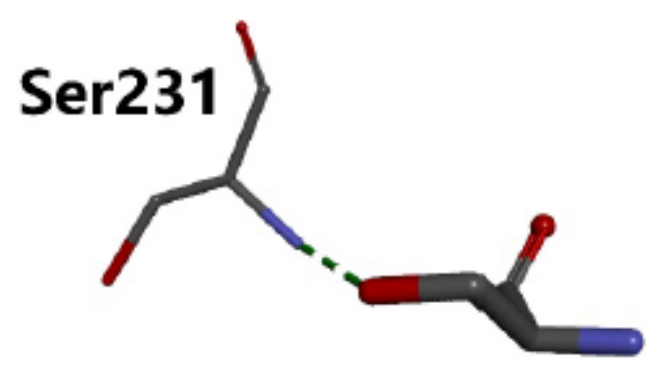

Ser229

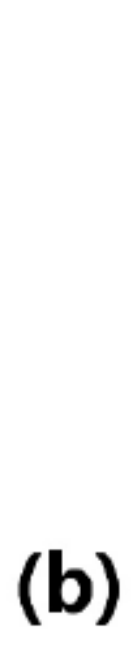

Mutant

Ser231

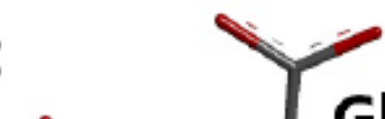

Glu232

\section{Figure 5}

Predicted changes in the tertiary structure of giant panda MIP caused by the missense mutation S229N. (a) Changes in surface structure visualized using Discovery Studio Visualizer. The yellow circle reveals a subtle but distinct protrusion in the mutant protein caused by the bulkier side chain of asparagine compared to serine. (b) Interactions between amino acid side chains predicted using THREADER and Modeller. The S229N mutant forms two new hydrogen bonds.

\section{Supplementary Files}

This is a list of supplementary files associated with this preprint. Click to download.

- SupplementalTable.pdf 